\title{
TRADUZIR AS METÁFORAS DO FUNDO DO CORAÇÃO (AMOR CORTÊS, METÁFORA E TRADUÇÃO) ${ }^{1}$
}

\section{Inês Oseki-Dépré}

Apesar de que questões literárias desse tipo, vastas e essenciais, exijam - a fim de serem tratadas de maneira exaustiva ${ }^{2}$ - um volume completo ou vários, propomos no presente artigo apenas sugerir algumas pistas e elaborar um esboço de análise que reúna o amor, a metáfora e a tradução.

Desse modo, após colocarmos previamente algumas observações gerais sobre a metáfora e a tradução, comentaremos em seguida um dos aspectos da questão examinando dois casos de metáforas amorosas utilizadas nas cansos trovadorescas, ou seja, a feudalidade, em relação aos jogos no primeiro e o canto dos pássaros no segundo.

Definições da metáfora não faltam; manteremos apenas três, das quais a do dicionário francês Petit Robert, a mais conhecida, é: figura de retórica e por extensão "procedimento da linguagem que consiste em uma transferência do significado por substituição analógica"; ou a do nosso Aurélio: "s.f. Figura de linguagem que consiste na transferência da significação própria de uma palavra para outra significação, em virtude de uma comparação subentendida".

Por seu lado, Dumarsais (1988) dedica um longo artigo à metáfora (translatio, transfert) definida como "uma figura pela qual se transporta, por assim dizer, a significação própria de uma palavra a uma outra significação que somente lhe convém em razão de uma comparação que se forma no espírito" (p. 135). Acrescenta que ela provém de uma comparação, e esse detalhe é interessante na medida em que, segundo os especialistas, os trovadores preferem a comparação à metáfora.

Para Mazaleyrat \& Molinié (1989), a definição é mais detalhada mas bastante próxima: "tropo segundo o qual a transferência semântica entre o significado do termo ocorrente e o significado do termo não trópico joga numa relação de comparação" (p. 213).

Se pensarmos que a tradução literária diz também respeito à metáfora enquanto operação de substituição de um texto (palavras) por um outro, ou seja, de uma operação

\footnotetext{
${ }^{1} \mathrm{O}$ texto da presente comunicação é a versão integral de uma comunicação apresentada no simpósio "Poéticas da tradução" (org. Marcelo Jacques de Moraes, Isabela Leal, Paula Glenadel e Masé de Lemos) do Congresso da ABRAPT, setembro de 2013. Uma versão francesa menos completa foi publicada na revista La Tribune Internationale des Langues Vivantes, 55, maio de 2013.

${ }^{2}$ V. Kay, 1990; Blakeslee, 1985; Cropp, 1975; Ménard, 1969.
} 
paradigmática, a questão da tradução da metáfora aparece oferecer uma dupla espessura. ${ }^{3}$ Quanto ao amor, a poesia medieval trovadoresca se caracteriza especialmente por esse tema. Ora, o que ocorre na tradução das metáforas amorosas nesse contexto?

À primeira vista, para o tradutor, nenhuma dificuldade suplementar parece ligada à tradução da metáfora, com exceção de dois casos: o caso em que o tradutor deixa escapar a metáfora filée, disseminada num texto e passada desapercebida; e o caso em que obstáculos linguísticos impediriam a transposição de uma língua para a outra. No primeiro caso, podemos dizer que o tradutor sofreu momentaneamente de uma afasia que constituiria numa “deficiência na seleção" ou uma carência do paradigma (Jakobson, 1963, p. 50-51). O tradutor, como afásico, pôde salvar o "arcabouço, as cadeias de conexão da comunicação", mas, no caso da metáfora, ele perdeu a figura completa e por conseguinte o efeito estilístico original.

No segundo caso, podemos citar múltiplos exemplos, assim segundo Jakobson: “é mais difícil permanecer fiel ao original quando se trata de traduzir, numa língua provida de uma certa categoria gramatical, a partir de uma língua que ignore essa categoria” (p. 83). Isso ocorre na tradução dos pronomes pessoais em vietnamita, por exemplo; toda a dificuldade de traduzir Madame Bovary nessa língua se dá na medida em que Flaubert joga com a ambiguidade pronominal e omite em certas passagens um pronome fixo, deixando ao leitor a liberdade de imaginar o sujeito do enunciado (trata-se do narrador, de um observador, de uma personagem, de Emma Bovary?). Em vietnamita, porém, é necessário marcar o gênero do sujeito (ele? ela?), às vezes a idade das personagens, daí a dificuldade quase insuperável que encontra o tradutor vietnamita.

Um outro exemplo é fornecido por Jakobson sobre o gênero (ou o sexo) das palavras. Para os dias da semana, os russos apreendem a segunda, a terça e a quarta-feira como seres masculinos, a quinta, a sexta e o sábado como seres femininos (os primeiros, poniel'nik, vtornik, cetverg são masculinos; os últimos, sreda, pjatnica, subbota, femininos). Jakobson observa ainda: “nas línguas eslavas e em outras línguas, em que 'dia' é masculino e 'noite” é feminino, o dia é representado pelos poetas como 'o amante da noite"” (p. 85). No nosso caso, todo tradutor do francês para o português afronta a inversão genérica do "mar" feminino em francês (la mer) e masculino em português. A representação poética não pode ser a mesma; la

\footnotetext{
${ }^{3}$ Trata-se de uma simplificação, evidentemente. Para Jakobson (1963), "mais frequentemente, porém, traduzindo de uma língua a uma outra, substitui-se as mensagens numa das línguas, não a unidades separadas mas a mensagens inteiras da outra língua" (p. 80), o que se realiza de maneira menos marcada na tradução da poesia (p. 82).
} 
mer (homófona de mère, mãe) é vivida como um "berço" pelos franceses mesmo quando encapelada, ao passo que em português, o mar se reveste de características por vezes viris e heroicas.

Um bom exemplo que pode ilustrar essa discrepância se encontra no poema de Haroldo de Campos “Thalassa, Thalassa” (Campos, 2006, p. 27), no qual a tradução deve substituir “o Mar” por “o Oceano”, o feminino não sendo viável:
Nous ne connaissons pas l'Océan
L'Océan viril et ses testicules d'or
L'Océan et son cœur cardinal aux feuilles vertes
Et ses immenses branchies de poisson emprisonné
L'Océan, non pas celui qui arrive dans notre dos
$[\ldots]$
Roi de Byzance et d'onguent mouvant parmi ses épouses
Leurs mains manucurées

Poderíamos ainda acrescentar o caso em que a metáfora (ou o tropo) é intraduzível, pois na língua de chegada ela perde todo significado. É o caso de imagens chinesas ou persas.

Felizmente, no exemplo que nos ocupa, e voltamos ao nosso assunto, a tradução da metáfora amorosa dos trovadores provençais em português não oferece tantas dificuldades, pela simples razão de são duas línguas romanas, ambas oriundas do latim e portanto possuindo traços similares. É verdade que a interpretação das figuras do amor é mais complexa se seguirmos a leitura de Ezra Pound ${ }^{4}$ e dos especialistas que veem, em Arnaut Daniel e em seus herdeiros Dante e Cavalcanti, a marca da mitologia greco-latina (pagã, portanto) sobre as figuras da liturgia cristã. Mas lá se trata de hermenêutica, o que não entra em nosso assunto.

$\mathrm{Na}$ antologia Verso/reverso/controverso, o poeta Augusto de Campos (1978) fornece uma série de traduções notáveis de vários poetas que vão dos trovadores provençais a Mallarmé. Antes de entrar na análise propriamente dita de suas traduções, faremos algumas observações sobre a tradução da metáfora amorosa da partida de xadrez/jogo de dados, ambos ju de cambre.

Com efeito, segundo Blakeslee (1985, p. 213-222), "na lírica dos trovadores, a metáfora amorosa do jogo de xadrez, que se coloca sob a rubrica geral das metáforas do jogo erótico, traduz por um lado a ideia do combate entre dois adversários de grande valor e por outro a do amor como um rito submetido a regras complexas e rígidas.”

\footnotetext{
${ }^{4}$ V. Pound (1960), especialmente "Psychology and troubadors".
} 
O jogo de xadrez, prossegue a autora, era considerado "o rei dos jogos e o jogo dos reis", ocupando um lugar privilegiado na vida aristocrática da França medieval. As razões eram que ele permitia pôr em valor as qualidades aristocráticas de inteligência e de instrução. O jogo de xadrez ocupava portanto um lugar importante nas crônicas medievais e nos romances enquanto meio de educação dos filhos da aristocracia (ao lado da equitação, das práticas de combate) e se praticava enquanto ju de cambre, na câmara da dama, inacessível às outras classes. Enquanto jogo de símbolos (reis, rainhas, cavaleiros, peões) ele correspondia exatamente à representação da sociedade hierarquizada das proezas guerreiras. Transmitido por textos árabes desde o século $\mathrm{X}$ via tradução, tornou-se rapidamente o paradigma das metáforas literárias. ${ }^{5}$

Blakeslee enumera os autores da Idade Média que, à maneira dos trovadores, a utilizaram em sua literatura, como Charles d'Orléans, Guiot de Provins, Raoul de Soissons, Conon de Bethune e Gautier de Coincy.

Ora, se as alusões ao jogo de xadrez constituíram um motivo importante entre os poetas d'oil, podemos encontrar metáforas amorosas em língua d'oc que a associam ao jogo de dados (joc coni, segundo Marcabru). As metáforas (ou alegorias) que o representam fazem portanto parte do código fin amors e designam em maioria os amores infelizes.

O jogo de dados, pelo contrário, mais livre e dependendo do acaso, apresenta um caráter de espontaneidade que, segundo Blakeslee, "incita à licença e ao gozo imediato". A metáfora do jogo de dados, como a metáfora do jogo de xadrez, reveste quase sempre um aspecto erótico e seja uma seja outra, as encontramos em $11 \%$ das peças dos trovadores (Rosenstein, 1980, apud Blakeslee, 1985, p. 216).

O poema seguinte, de Guilhem de Peitieu (Jeanroy, 1913, p. 15), que se gabava de ser maiestre certa, mestre infalível na arte de seduzir a dama, se baseia de maneira ambígua na palavra taulier, que pode se entender como tabuleiro (de damas? de xadrez?) ou ainda como "avental" (tablier, em francês). No Canto VI, o poeta americano e modelo da tradução contemporânea, Ezra Pound, incorpora referências ao trovador, cuja fertilidade é exibida também no poema "Vers", que vamos analisar, onde o poeta se vangloria de seu extraordinário recorde de virilidade.

\footnotetext{
5 "De origem persa, malz, que significa etimologicamente 'morte' (Ar. Mat), possui toda uma escala de significações provindas de uma contaminação do vocábulo árabe pelo adjetivo latim matta 'apagado' e por extensão, 'triste'. Na língua d'oc, malz recobre quatro domínios semânticos: (1) o jogo de xadrez; (2) a dor e a tristeza; (3) a loucura (o 'louco') e enfim (4) a violência e a morte [...] Essa polissemia está na origem de numerosos jogos de palavras do trobar clus: o amante está infeliz por amor, procura submeter-se à dama, declara-se malz, vencido, ou, ao contrario, tem a intenção de matar (mate), de lhe impor sua vontade, seu desejo" (Blakeslee, 1985, p. 217).
} 
What you have done, Odysseus,

We know what you have done...

And that Guillaume sold out his ground rents

(Seventh of Poitiers, Ninth of Aquitain).

"Tant las fotei com auzirets

"Cen e quatre vingt et veit vetz..."

The stone is alive in my hand, the crops will be thick in my death-year...

Till Louis is wed with Eleanor

And had (He, Guillaume) a son that had to wife

The Duchess of Normandia whose daughter

Was wife to King Henry e maire del rei jove...

Segundo o crítico Alfred Jeanroy (1913, p. xvii), "Guilhem não se apresenta jamais como indigno da mulher amada e não se estende nunca em protestos de humilhação. Não somente o amor não assume um caráter platônico para ele, mas a expressão do desejo sensual reveste-se de formas bem cruas, por vezes brutais." Para Augusto de Campos, seu tradutor, o poeta provençal é também capaz de requinte cortês ou ainda de fazer bem versos sobre quase nada. Dito isso, ele permanece sendo o precursor da geração realista da poesia trovadoresca do qual vão derivar as "Cantigas de escarnio e de maldizer", gênero muito apreciado mais tarde pelos trovadores galego-portugueses. Essa razão e sua posição no conjunto dos trovadores explicam, sem dúvida, a escolha do poeta brasileiro.

A canso do trovador é assaz simples; ela gira em torno da maiestra certa de Guilhem de Peitieu ${ }^{6}$, o poeta se gabando de ser sempre bem sucedido nos seus golpes amorosos, sua reputação estando já feita nesse domínio. O "lance de dados" vai ser confirmado: trata-se de um poema erótico.

A metáfora do "jogo" está presente em quase em todo o poema, e se ela não corresponde às regras estritas da comparação com o jogo de xadrez, a razão é sem duvida o aspecto pioneiro do trovador, o primeiro a cantar o amor, aqui o amor erótico.

\section{I.}

A tradução de Augusto de Campos segue os mesmos princípios poéticos que ele põe em prática para traduzir o conjunto trovadoresco: o número de versos e as rimas são escrupulosamente respeitados, apesar de aparecerem em maior número na tradução (-or, $-i,-a$, er em Guillhem de Peitieu e -or, -ura, -em, -im, -ão, -eito, -osa, -ez, -eiro para Augusto de

\footnotetext{
${ }^{6} 7^{\circ}$ conde de Poitiers, $9^{\circ}$ d'Auitaine, Guilhem de Pieitieu (1071-1127), herdeiro de domínios mais vastos que os do rei de França entre os provençais. De sua obra restam 11 poemas. Também conhecido como Guilhaume d'Aquitaine.
} 
Campos). O tradutor substitui o titulo "Vers" ("Verso" ou "Versos") por "O lance de dados" ("Le coup de dés") que ele retoma na estrofe 7, onde o trovador diz cap (coup) sem adjetivo, numa homenagem evidente a Mallarmé. Ora, por meio de uma referência intertextual, ele precisa o teor do jogo, até agora deixado ambíguo: trata-se bem do jogo de dados.

Outras substituições aparecem, numerosas, que permitem manter o esquema métrico e rítmico do original.

Assim, no v. 3, est. 1: "Et es vertaz", que rima com "Quant er lassatz", é aqui substituído por "Ninguém me bate", que rima com "Dado o remate". Observe-se que o particípio passado do verbo "dar" é um homófono de "dado". O poeta realiza igualmente inversões: v. 2, est. 2: "E conosc anta e honor", traduzido por "Conheço honra e desventura", que vai rimar com outras palavras em -ura ("ardimen e paor", traduzido por "pavor e bravura", v. 3, mesma estrofe).

A referência ao jogo $(j u)$ aparece na estrofe 4, na qual se trata do mestier infalível do trovador que sabe jogar ("jogar sobre coyssi”) sobre a almofada, o divã. Na estrofe 5, uma referência é feita a Deus e a São Juliano, Jolia em provençal, o que acarreta uma rima em -ão e não em - a. "Ni us de mi noa tornara/ Descosselhatz", vv. 6 e 7 da mesma estrofe, que serão traduzidos pela afirmação: "As que vierem voltarão/ Sabendo o jogo" - com uma precisão do gênero do sujeito (ninguém será desaconselhado a se tornar: "as que virão retornarão conhecendo o jogo...”)

Em suma, Augusto de Campos, por meio de sua escolha lexical, constrói de maneira mais clara uma métaphore filée do jogo de dados, mais vaga no original, reforçando a alusão a Mallarmé. Assim, no v. 5 da est. 6, onde o trovador diz: "Tan ensenhatz" (bem informado), o poeta brasileiro traduz por "Tenho tal arte", que pode ser considerado como uma expressão metalinguística se referindo à arte do próprio verso e que continua a alusão ao "Lance de dados" (“Coup de dés").

A partir da estrofe 7, Guilhem muda de registro: passa da descrição de suas qualidades de "maiestre certa" a uma ilustração, à narração de uma aventura, que tende a provar suas capacidades. Aí também Augusto de Campos introduz uma nota "metalinguística" (moderna): enquanto no original encontramos "Pero no m'auzetz tan guabier" (não me gabo em vão), no V. 1, est. 7, Augusto de Campos traduz por "E não me digam que isto é prosa", com suas duas significações: "não me digam que estou contando lorotas", e a que afirma o caráter de poema, que não é prosa mas poesia.

Uma dama tendo se recusado ao trovador (xeque- mate), ele responde que vai desafiála (xeque-mate): levanta o "avental" ("taulier") da dama, traduzido por "avental xadrez", joga 
os dados ("Empeis los datz") dos quais o terceiro atinge o centro, os dados foram lançados. A tradução, quanto a ela, atinge aqui uma das metas principais do tradutor, o rejuvenescimento de Goethe, o make it new de Ezra Pound.

Aqui pode-se contestar que a metáfora do ju de cambre não é exatamente uma "metáfora do fundo do coração", apesar de o desejo que a anima poder sê-lo. Já não é o caso de "L'aura amara" d'Arnaut Daniel, "il miglior fabbro" segundo Dante, traduzido igualmente por Augusto de Campos.

Vers

1. Ben vuelh que sapcho li pluzor D'est vers si's de bona color, Qu'ieu ai trag de mon obrador : Qu'ieu port d'ayselh mestier la flor, Et es vertaz,

E puesc ne traire'l vers auctor Quant er lassatz.

2. Ieu conosc ben sen e folhor, E conosc anta et honor, Et ai ardimen e paor ; E si'm partetz un juec d'amor No suy tan fatz

No'n sapcha triar lo melhor D'entre'ls malvatz.

3. Ieu conosc ben selh qui be'm di, E selh qui'm vol mal atressi, E conosc ben selhuy qui'm ri, E si'l pro s'azauton de mi, Conosc assatz,

Qu'atressi dey voler lor fi E lor solatz.

4. Mas ben aya sel qui'm noyri, Que tan bo mestier m' eschari Que anc a negu non falhi ; Qu'ieu sai jogar sobre coyssi A totz tocatz;

Mais en say de nulh mo vezi, qual que'm vejatz.

5.Dieu en lau e Sanh Jolia :

Tant ai apres del juec doussa Que sobre totz n'ai bona ma, E selh qui cosselh mi querra Non l'er vedatz, Ni us de mi noa torna Descosselhatz.

\section{Lance de dados}

Quero que saibam o valor Da canção, se de boa cor, Que elaborei com meu calor; Neste mister eu levo a flor, Ninguém me bate, Irei prová-lo assim que for Dado o remate.

Conheço bem senso e loucura, Conheço honra e desventura, Já senti pavor e bravura;

Mas se propõem jogo de amor Não fico atrás;

Escolho sempre o que é melhor Do que me apraz.

Conheço bem quem me quer bem E sei quem me quer mal também, Quem ri de mim, quem me convém, E se de mim se achega alguém Sei muito mais:

Como saber prezar a quem Prazer lhe faz.

Bem haja aquele de onde vim, Pois que soube fazer de mim Alguém tão bom para esse fim; Que eu sei jogar sobre coxim De qualquer lado;

Não há ninguém que o faça assim, Por mais dotado.

Bendigo a Deus e a São Julião

Por tão bem cumprir a missão

E jogar com tão boa mão.

Se alguém precisa de lição

Que venha logo:

As que vierem voltarão

Sabendo o jogo. 
6. Qu'ieu ai nom « maiestre certa »:

Ja m'amigu' anueg no m'aura

Que no'm vuelh'aver l'endema

Qu'ieu suy d'aquest mestier, so'm va, Tan ensenhatz

Que be'n sai guazanhar mon pa En totz mercatz.

7. Pero ne m'auzetz tan guabier Qu'ieu non fos rahusatz l'autr'ier, Que jogav'a un joc grossier, Que'm fon trop bos al cap primier Tro fuy 'ntaulaz;

Quan guardiey, no m'ac plus mestier Si'm fon camjatz.

8. Mas elha'm dis un reprovier ; « Don, vostre dat son menudier, Et ieu revit vos a doblier».

Fis m'ieu : "Qui'm dava Monpeslier, Non er laissatz ».

E leviey un pauc son taulier, $\mathrm{Ab}$ ams mos bratz.

9. Et quant l'aic levât lo taulier, Empeis los datz,

E'ill duy foron cairavallier, E'l terz plombatz.

E fi'ls fort férir al taulier E fon joguatz.
Chamam-me "o mestre sem defeito":

Toda mulher com quem me deito

Quer amanha rever meu leito;

Neste mister sou tão perfeito,

Tenho tal arte,

Que tenho pão e pouso feito Por toda a parte.

E não me digam que isto é prosa.

Ainda outro dia tive a prova,

Jogando uma partida nova.

Sai-me bem no meu primeiro Lance de dados;

Não vi os de nenhum parceiro Tão bem jogados.

Mas ela disse, com desprezo;

"Os vossos dados não têm peso,

Vos desafio a uma outra vez".

E eu; "Montpelier não vale o preço

Destes pedaços".

E ergui-lhe o avental xadrez

Com os dois braços.

Depois de erguer o tabuleiro, Joguei os dados;

Dois foram cair colados, E o terceiro

Feriu no meio o tabuleiro, E estão lançados.

II.

Em Verso/reverso/controverso, um grande espaço é consagrado por Augusto de Campos à apresentação da poesia trovadoresca, quer em seus aspectos históricos e contextuais, quer em seus aspectos técnicos, sobre os quais, por seu lado, o poeta francês Jacques Roubaud coloca ênfase. ${ }^{7}$ Assim, após ter analisado a "fórmula" da canso (tripla: métrica, rítmica e melódica), este último expõe os princípios da rima yrsuta, utilizada por Arnaut Daniel, e que é aquela cuja sonoridade é quebrada, explosiva, seca: são as rimas “caras" cujos mestres são Raimbaut d'Orange e Arnaut Daniel. Ao mesmo tempo, Roubaud (1971) afirma que o primeiro princípio das coblas provençais é o "renovamento", ou seja, a originalidade da totalidade da fórmula (em sua cobla inicial). E acrescenta: "Certas formas que comportam versos breves [...] podem aparecer como múltiplas se considerarmos os versos longos como 'restituídos' a partir dos versos breves cujas rimas aparecem como 'rimas

\footnotetext{
${ }^{7}$ Numa perspectiva diferente, já propusemos uma primeira análise desse poema para o colóquio sobre traduções antigas ocorrido na Sorbonne (10/11/2012): "Pratiques d'hier et d'aujourd'hui", org. Joëlle Ducos \& Joëlle Gardes-Tamine). Ver "Des troubadours à la modernité; un parcours amoureux?".
} 
internas'." É o caso da canso de Arnaut Daniel, "L'aura amara”, poema igualmente traduzido entre outros por Ezra Pound. Segundo o poeta americano, "todo estudo da poesia europeia seria falsificado se não começasse por um estudo da arte da Provença."8

No que diz respeito a nossa problemática, encontramos nesse poema várias metáforas trançadas onde se trata da natureza e das relações feudais (a dama é comparada ou representada pela dona e o poeta pelo pajem). Com efeito, em relação a essa última, das cinco categorias propostas pelo Vocabulaire courtois des troubadours de l'époque classique (Cropp, 1975, p. 473 segs.) que correspondem aos aspectos essenciais da homenagem vassálica - a traditio personae, os ritos, as obrigações do chefe, as obrigações do subalterno, a violação dos juramentos — encontramos o caso do pretendente ("l'amoureux") que se submete à dama: “qui m'a virât bas d'aut", que me jogou de cima para baixo, est. 1, v. 15, que pertence à traditio personae; a homenagem (os ritos): “qu'al sieu servir sui del pe tro c'al coma”, que a seu serviço, ser dos pés à cabeça, est. 2, v. 17; “que d'als jauzir no'm val jois una poma", que seu valor/ é mais que toda soma, v. 15, est. 4; as obrigações do subalterno em “qu'al sieu servir", seu servidor, v. 16, est. 2; “al rei qui t'er escuoills”, v. 4, est. 6, ao rei em homenagem.

Jacques Roubaud lembra que a dona é quase sempre chamada de "midons" ("ma seigneur"), passada na arte trovadoresca galego-portuguesa, revestindo assim um caráter ambíguo, dotada de um duplo sexo e de um duplo papel, ao mesmo tempo dama e senhor. O poeta cita as ocorrências desse termo em vários trovadores tais como Raimbaut d'Orange, Guiraut de Calanson, Bernart de Ventadour e Guilhem IX.

Sobretudo, o ponto para o qual os grandes tradutores como Augusto de Campos, Ezra Pound ou Jacques Roubaud chamam a atenção é o caráter "metafórico" da forma do poema, em que, com efeito, encontramo-nos diante de uma estética do som.

A "música" do verso, sua melopeia, seja no nível das aliterações, onomatopeias, paronomásias ou do ritmo, staccato, tudo remete àquilo de que se fala no poema: as batidas pesadas e leves e rápidas, características do trobar clus, representam o sopro do ar que faz cair as folhas, calar os pássaros ou embranquecer os bosques (v. 1 a 5). Segundo Ezra Pound: "in l'aura amara he cries as the birds in the autumn [...] we have the chatter of birds in autumn. The onomatopoeia obviously depends upon the 'utz' 'entz' 'encs' 'atz'... of the rhyme scheme" (Pound apud Roubaud, 1971, p. 226). Eles remetem igualmente às batidas do coração.

\footnotetext{
${ }^{8}$ Ezra Pound, The Spirit of Romance (1910), Make it new (1934), The Translations of Ezra Pound (1953), Literary Essays of Ezra Pound (1954), apud Campos, 1978, p. 9.
} 
Para Jacques Roubaud, “leur parler (des oiseaux), leur 'latin' est celui de l'amour. Ils chantent sa douceur, sa suavité. Ils chantent le printemps courtoisement puisqu'ils savent l'amour; puisqu'ils souffrent l'amour" (Roubaud, 1971, p. 7-8). Assim, o rouxinol aparece tanto em Peire Vidal quanto em Gaucelm Faidit, Jauffre Rudel, Marcabru, Vernart de Ventadour; a cotovia em Raimbaut d'Orange ou Bernart Marti. Em Arnaut Daniel os nomes de pássaros não são especificados, porém as sonoridades surdas apoiadas em monossílabos remetem ao canto dos pássaros (v. 6 a 8, estrofe 1 e mais adiante, V. 5 a 8, estrofe 3). Roubaud salienta o carácter mimético da arte de Arnaut Daniel.

A presença desse "ar amargo" remete por outro lado à dona, indiferente ao amor de seu vassalo e cuja "luz do olhar" (estrofe 2) grava sua imagem no coração. A referência à religião não falta, como sugere Pound, no último verso da estrofe 6 e no último verso da estrofe 7, em que é questão de Roma. Observe-se que a primeira palavra do poema "L'aura" será retomada por Petrarca em suas Stanze a Laura... ${ }^{9}$

Este vocábulo é o um dos raros que Augusto de Campos não pôde transpor em sua tradução, apesar de respeitar rigorosamente os esquema das rimas (externas e internas) e o ritmo. A apresentação vertical que ele propõe, como a de Pound, torna mais acessível a visualização do esquema rítmico acrescentando-lhe ao mesmo tempo um aspecto bastante moderno (contemporâneo). Pode-se notar a presença de alguns procedimentos próprios a sua poesia, quando isola habilmente, por exemplo, a primeira sílaba da palavra: "car-" (-come), produzindo uma rima para o olho com "olhar", "provar", "pervagar", "doar", na estrofe 1, procedimento que ele vai repetir mais adiante (“cor-", v. 3, est. 2, que rima com "cor", est. 2, e com "tor-", est. 3).

O que distingue esse poema em 6 estâncias de 7 versos de 8 a 10 metros cada, "o mais prodigioso esforço da virtuosidade provençal” segundo André Berry é, por outro lado, embora a fórmula do poema seja "simples", a cobla estramp de 7 versos, caracterizada pela repetição do paradigma sonoro a cada verso de todas as estrofes; assim para o primeiro verso: "amara", est. 2, "Clara", est.3, "gara", est. 3, "m'ampara", est. 4, "car'a”, est. 5 e "para”, est. 6; no segundo verso "brancutz", "lutz", "vengutz", "tralutz", "volguz","condutz"; no terceiro "clarzir", "d'eslir", "C'auzir", "d'alzir", "sofrir", "formir". As assonâncias e rimas se desdobram de estrofe em estrofe e não somente as interiores, o que a tradução mantém de maneira notável: “amara”, “clara”, "para”, “ampara”, "cara”, “prepara” nos primeiros versos;

\footnotetext{
${ }^{9}$ Ver Roubaud: “A la suite de Dante, Pétrarque fera à Arnaut l'honneur d'emprunter la forme (qui sera nommée par lui) de la sextine assurant à la fois son existence comme forme nouvelle (héritage, comme le sonnet, de la canso) et sa survie" (p. 225).
} 
“car-“, "olhar”, "provar”, “orar”, "pervagar”, “doar” e assim por diante. Esse conjunto de "contraintes" (obrigações) inspirou os autores do OULIPO, que pretendem ser os herdeiros de certa maneira dos trovadores provençais. ${ }^{10}$

Nesse sentido, Augusto de Campos nota que, ainda na primeira estrofe ou estância (a que dá o tom do poema), Arnaut constrói uma série alfabética: aura amara/bruoills brancutz/ clarzir/ doutz/ espeissa ab fuoillis... que o tradutor mantém em português: "aura amara/ branqueia os bosques/ car-come a cor/ da espessa folhagem." Campos mantém portanto a alternância entre "batidas pesadas" e "batidas leves e rápidas" numa relação isomórfica com a regra original.

O curioso é que a tradução de Jacques Roubaud, mestre da "contrainte", se apresenta de maneira completamente diferente, respeitando a disposição do original embora utilizando a sextina. Apresentamos aqui um trecho de sua tradução:

L'air amer fait les bois branchus s'éclaircir que le doux
épaissit de feuilles et les joyeux becs des oiseaux rameux
rend balbutians muets en couples on non-couples ce
pourquoi je m'efforce de faire et dire choses agréables à
plusieurs pour celle qui m'a jeté à bas de haut dont je crains
de mourir si la douleur elle n'arrête

Roubaud se explica quanto à dificuldade de traduzir o poema em versos dada a "crise do verso" proferida por Mallarmé: foi-lhe impossível traduzir tampouco em versos livres. Além disso, a proximidade da língua provençal, parente do francês, acrescenta dificuldades insolúveis: a solução que consistiria na "arcaização" do francês para significar a distância cronológica não lhe pareceu viável. A "solução" encontrada pelo grande poeta foi de traduzir "à la lettre", literalmente, o que além de manter uma certa fidelidade ao original, responde à proposta benjaminiana: "É por que, principalmente na época em que ala aparece, o maior elogio que se possa fazer a uma tradução não é que ela se leia como uma obra original de sua língua"... e conclui: “a verdadeira tradução é transparente, não esconde o original, não se põe diante de sua luz" (Benjamin, 1971). Uma outra maneira de traduzir, que se explica no contexto francês e que ilustra de certa maneira, a aporia benjaminiana.

Concluindo, podemos afirmar que se a rede metafórica utilizada por Arnaut Daniel faz parte do código Amors fin, portanto é familiar aos trovadores provençais; podemos também

\footnotetext{
10 “De manière générale, n'ayant pas d'imagination, je n'invente pas. Je soumets les données du monde extérieur - livresque ou autre - à des procédés, à des contraintes... C'est, plus généralement [...] un certain retour à une esthétique médiévale qui détestait l'originalité", entrevista de Jacques Roubaud em Kuon, 1999, p. 199-200.
} 
dizer que seu poema se reveste de um aspecto mimético que faz dele mesmo uma metáfora do amor, portanto da poesia medieval, qualidade que soube preservar seu grande tradutor, Augusto de Campos, talvez "il miglior tradutore" d'Arnaut Daniel.

\section{L'aura amara}

L'aura amara

fa'ls bruoils brancutz

clarzir,

que 1 doutz espeissa ab fuoills,

e ls letz

becs

dels auzels ramencs

ten balps e mutz,

pars

e non pars ;

per qu'eu m'esfortz

de far e dir

plazers

a mains per liei

que m'a virât bas d'aut,

don tem morir

si ls afans no m'asoma.

Tant fo clara

ma prima lutz

d'eslir

lieis, don cre 1 dors los huoills

non pretz

necs

mans dos aigonencs,

d'autra s'eslutz

rars

mos preiars ;

pero deportz

m'es e d'auzir

volers,

bos motz ses grei

de liei don tant m'azaut

qu'al sieu servir

sui del pe tro c'al coma.

Amors, gara !

Sui ben vengutz?

C'auzir

Tam far, si'm dezacuoillis,

tals detz

pecs

que t'es mieills que $t$ trencs ;

qu'ieu soi fis drutz

cars

e non vars ;

\author{
Aura amara \\ branqueia os bosques, car- \\ come a cor \\ da espessa folhagem. \\ Os \\ bicos \\ dos passarinhos \\ ficam mudos, \\ pares \\ e ímpares. \\ E eu sofro a sorte : \\ dizer louvor \\ em verso \\ só por aquela \\ que me lançou do alto \\ abaixo, em dor \\ má dama que me doma.
}

Foi tão clara

a luz do seu olhar

que no meu cor-

ação gravou a imagem.

Dos

ricos

rio, seus vinhos,

damas e ludos

parec-

em-me vulgares.

Só tenho um norte:

morrer de amor

imerso

no olhar da bela

que me tomou de assalto,

seu servidor

ser, dos pés à coma.

Amor, para!

Que queres mais provar?

É inútil tor-

turares o teu pajem,

só os

picos

dos teus espinhos

pontiagudos

dares,

flor negares. 
ma 1 cors ferms fortz

mi fai cobrit

mains vers,

qu'ab tot lo nei

m'agr'ops us bais al chaut

cor refrezi

que no i vai autra goma

Si m'ampara

cill que $\mathrm{m}$ tralutz

d'aizir

si qu'es de pretz capduoills, del quetz

precs,

c'ai dedinz a rencs,

l'er fort rendutz

clars

mos pensars ;

qu' eu fora mortz,

mas fa'm sofrir

l'espers

que ill prec que $m$ brei,

c'aisso $m$ ten let e baut,

que d'als jauzir

no $\mathrm{m}$ val jois uma poma.

Doussa ca'ra

totz aibs volgutz,

sofrir

m'er per vos mainz orguoills,

quar etz

decs

de totz mos fadencs,

don ai mains brutz

pars.

E gabars

de vos no $m$ tortz,

ni $m$ fai partir

avers,

c'anc non amei

ren tant ab meins d'ufaut ;

anz vos désir

plus que Dieu cill de Doma.

Era t para,

chanz e condutz,

formir

al rei qui t'er escuoills ;

car pretz,

secs

sai, lai es doblencs,

e mantengutz

dars

e manjars.

De joi 1 a t portz,
A alma é forte,

mas o cor-

po inverso

já se rebela

e quer de um salto

colher a flor

de boca, beijo e aroma.

Se me ampara,

essa a quem vivo a orar,

no calor

da sua hospedagem,

jus-

tifica os

meus descaminhos,

muda os

pesares

dos meus pensares.

Mas antes morte

me propor

adverso

do que perdê-la

meu sobressalto.

Que o seu valor

é mais que qualquer soma.

Face cara

que me faz pervagar

sem temor,

atrás de uma miragem,

nos

becos,

pelos caminhos

mais desnudos,

por ares

e por mares,

em louco esporte.

Surdo ao Rumor

perverso,

somente a ela

sobreamo, falto

de senso, amor

maior que a Deus tem Doma.

Vai, prepara

canções para doar,

trovador,

ao rei homenagem.

Rús-

ticos

pães, duros linhos

serão veludos,

rarís-

simos manjares.

Parte com porte. 
son anel mir

si 1 ders,

c'anc non estei

jorn d'Arago que 1 saut

no i volgues ir,

mas sai m'a clamat Roma

Faitz es l'acortz

qu'el cor remir

totz sers

lieis cui domnei

ses parsonier, Arnaut ;

qu'en autr'albir

n'es fort m'entent'a soma.
Embora em dor

subverso,

veneral o anel. A

Aragon, baldo,

vai teu ardor,

pois quem comanda é Roma.

Ei-la em seu forte.

Combatedor

converso,

em sua cela

sou prisioneiro, Arnaldo.

Esse sabor

de amar ninguém me toma.

\section{Referências bibliográficas:}

BENJAMIN, Walter. La tâche du traducteur. In : Mythe et violence. Paris: Denoël, 1971.

BLAKESLEE, Merritt R. Lo dous jocx sotils : la partie d'échecs amoureuse dans la poésie des troubadours. Cahiers de civilisation médiévale, année 85, vol. 28, n. 110-1, p. 213 $222,1985$.

CAMPOS, Augusto de. Verso/reverso/controverso. São Paulo: Perspectiva, 1978.

CAMPOS, Haroldo de. Une anthologie. Proposta e tradução de Inês Oseki-Dépré. Paris: Al Dante, 2006.

CROPP, Glynnis M. Vocabulaire courtois des troubadours de l'époque classique. Vol. 1. Genebra: Droz, 1975.

DUMARSAIS, César C. Des tropes ou des différents sens. Paris: Flammarion, 1988.

JAKOBSON, Roman. Essais de linguistique générale. Paris: Minuit, 1963.

JEANROY, Alfred. Les chansons de Guillaume IX. Paris: H. Champion, 1913.

KAY, Sarah. Subjectivity in Troubadour poetry. Cambridge: 1990.

KUON, Peter (org.) Oulipo-Poétiques. Tübingen: Cunther Narr, 1999.

MAZALEYRAT, Jean, \& MOLINIE, Georges. Vocabulaire de la stylistique. Paris: PUF, 1989.

MENARD, Philippe, Le rire et le sourire dans le roman courtois en France au Moyen Age (1150-1250). Genebra: Droz, 1969.

POUND, Ezra. The spirit of Romance. Londres: Peter Owen, 1960 [1910]. 
ROSENSTEIN, R. S. Jocus amoenus: love, play and poetry in troubadour lyric. Tese de doutorado, Columbia University, 1980.

ROUBAUD, Jacques. Les troubadours. Paris: Seghers, 1971. 